\title{
Biological features of lactic acid bacteria in distinct ecological niches
}

\author{
T.N. Orlova ${ }^{1}$, R.V. Dorofeev ${ }^{1}$, A.N. Irkitova ${ }^{2}$, I.A. Funk ${ }^{1}$, A.V. Grebenshchikova ${ }^{2}$ \\ ${ }^{1}$ Federal State Budgetary Scientific Institution «Federal Altai Scientific Centre of Agro-BioTechnologies», \\ Barnaul, Russian Federation \\ ${ }^{2}$ Altai State University, Barnaul, Russian Federation. E-mail: Elen171987@mail.ru
}

\section{Received: 14.08.2019. Accepted: 26.09.2019}

\begin{abstract}
Lactic acid bacteria are ubiquitous and occupy various ecological niches. These microorganisms are widely used in various industries due to their high and diverse enzymatic activity. Industry collections of microorganisms with technological valuable properties are created for the construction of bacterial sourdough compositions. The aim of our study was to study mesophilic Lactococci isolated from various ecological niches. Only 9 cultures (out of 100 strains of mesophilic Lactococci isolated from plants) can be attributed to promising for further use in industry. The proportion of strains with industrially valuable properties among animal lactobacilli was $19 \%$ higher. Therefore, objects of animal origin are the most appropriate source for isolation of mesophilic Lactococci strains, promising for use in the dairy industry.
\end{abstract}

Key words: Lactic acid bacteria; Mesophilic lactococci; Ecological niches; Bacterial compositions.

\section{Introduction}

Lactic acid bacteria can rightfully be attributed to one of the common groups of microorganisms. Representatives of this group of bacteria are ubiquitous and occupy a wide variety of ecological niches: parts of plants (leaves, flowers, rhizosphere), fruits, vegetables, raw milk, dairy products of non-industrial production, the surface of the skin, the gastrointestinal tract of animals and humans, etc. (Dworkin, 2006; Orlova, Irkitova, 2015; Tsugkiev et al., 2015).

One of the most important properties of lactic acid bacteria in natural microbial communities is their antagonistic activity against opportunistic and pathogenic microorganisms. Lactobacilli are able to produce a significant amount of lactic acid, antibiotic-like and other biologically active substances that have a significant effect on the biochemical activity of extraneous microflora (Ali, 2010).

Lactic acid bacteria play an important role in human life. Since our birth, lactobacilli have been involved in maintaining the balance of intestinal microflora, improving metabolic processes and increasing nonspecific resistance of the body. They actively participate in enzymatic processes, perform vitamin-forming and antagonistic functions, and improve indicators of protein, lipid and mineral metabolism (Shan, 2007; Solovyova et al., 2010; Khazagaeva et al., 2011; Sharma et al., 2012; Steele et al., 2013; Ganina, Filchakova, 2018).

The high and diverse enzymatic activity of lactic acid bacteria led to their widespread use in various industries (dairy, meat, pharmaceuticals, industrial biotechnology, agriculture, etc.) (Mayra-Macinen, Bigret, 2004; Mathur, Singh, 2005; Rozhkova, 2006; Panesar, 2011).

The ability to ferment lactose is a unique biological property of lactic acid bacteria, due to which they are actively used in the dairy industry in the form of artificially created microbial consortia (bacterial starter compositions) in the production of fermented dairy products (Leroy, 2004; Liu et al., 2011; Ganina et al., 2015; Novokshanova et al., 2016; Ganina et al., 2018).

To construct artificial microbial communities in the form of bacterial sourdough compositions, industry-specific collections of microorganisms with technologically valuable properties are created. Natural selection of lactic acid bacteria is the basis for the creation and maintenance of an industrial collection of microorganisms. The objects for highlighting promising strains of lactobacilli are the above ecological niches. It should be noted that the ecological niche largely determines the species diversity of lactic acid bacteria and their biological properties. For example, mesophilic lactic acid bacteria are more often isolated from raw milk and plant surfaces in temperate geographical areas, Streptococcus thermophilus - from natural objects of subtropical climate, Lactobacillus acidophilus - from the gastrointestinal tract of warm-blooded animals and humans, due to specific environmental conditions (Babich et al., 2015).

Most lactic acid bacteria isolated from various natural sources do not meet the requirements for sourdough microorganisms in the dairy industry. In addition, strains of lactic acid bacteria that are part of the bacterial compositions often lose their technologically valuable properties when stored. Therefore, to maintain and replenish the collection fund of microorganisms, it is necessary to constantly work on the selection of promising strains of lactic acid bacteria, which can later be used to create bacterial sourdough compositions in the production of fermented dairy products.

Due to the relevance of this problem, the aim of our study was to study the biological properties of lactic acid bacteria isolated from various natural sources.

\section{Materials and Methods}

The objects of research were cultures of mesophilic Lactococci isolated from animal objects (cow's milk-raw materials, goat's milkraw materials) and plant (aerial parts of plants) origin. The work used standard and generally accepted methods of microbiological analysis (Bannikova et al., 1975; Kvasnikov, Nesterenko, 1975; Bannikova et al., 1987; MR 2.3.2.2327-08, 2008). The studies were carried out on the basis of the laboratory of microbiology of milk and dairy products of the Siberian Scientific Research Institute of 
Cheesemaking Department of the Federal State Budget Scientific Institution Federal Altai Scientific Center for Agrobiotechnology (FSBSI FASCA).

Pure cultures of lactic acid bacteria were isolated by repeated passage into sterile skim milk and then grown at optimal temperatures for each group of microorganisms.

The isolated cultures of lactobacilli were studied according to the following biological and technologically valuable properties: the time of clot formation in skim milk, organoleptic evaluation, the activity of acid formation, gas formation and aroma formation.

\section{Results}

The 200 strains of lactic acid bacteria belonging to Lactococcus spp. (100 strains from plant objects, 100 strains from objects of animal origin) were identified for research work (Figure 1).

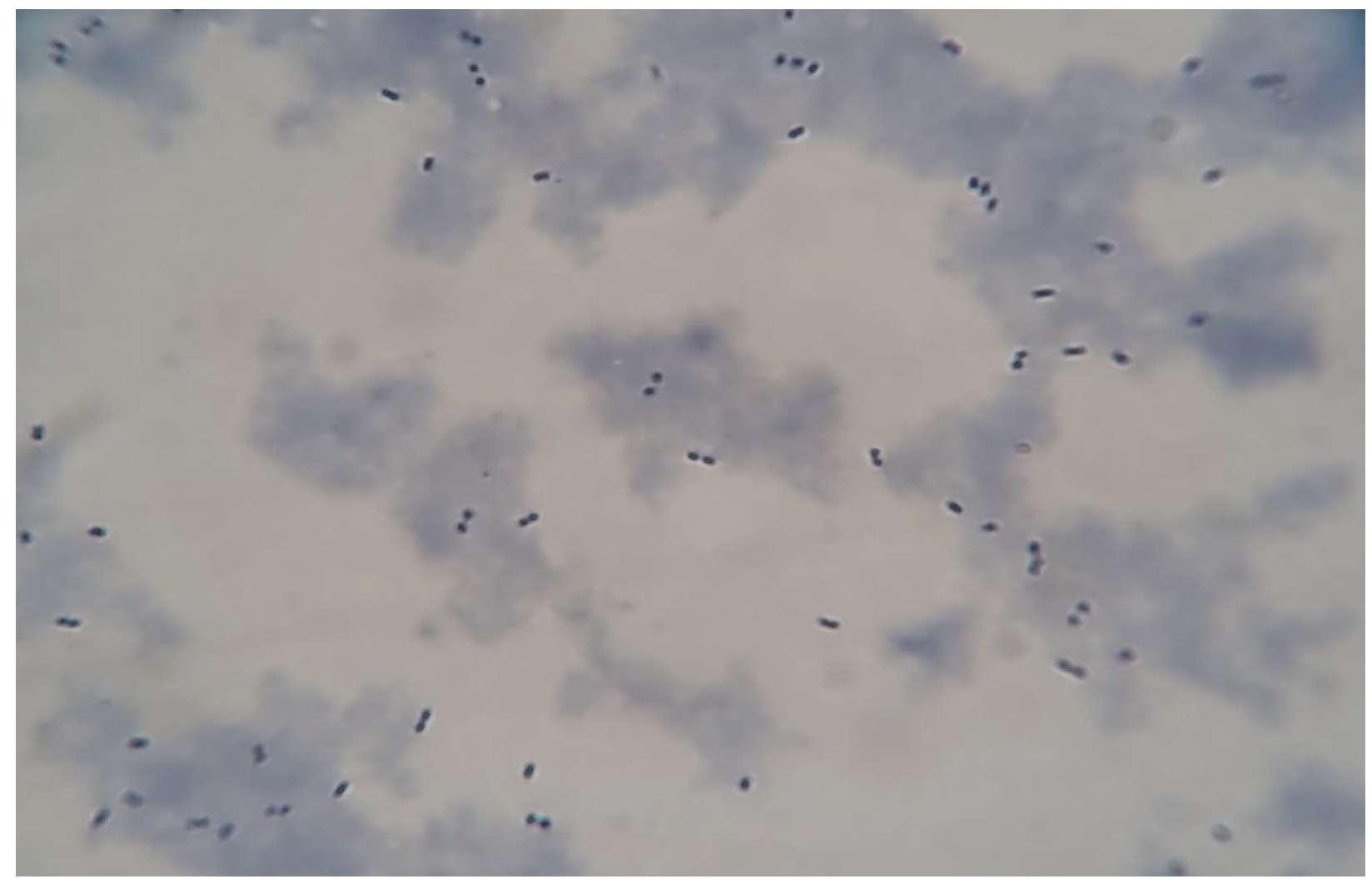

Figure 1. Microscopic preparation of a Lactococcus sp. strain isolated from an object of natural origin

The belonging of the selected cultures of lactobacilli to Lactococcus spp. were determined using the key properties specified in the ninth edition of the Bergey's Manual (Vos et al., 2009). A comparative analysis of some biological features of Lactococcal strains isolated from objects of plant and animal origin is shown in Table 1.

Table 1. Comparative analysis of some biological and technologically valuable indicators of mesophilic lactococcus strains of plant and animal origin

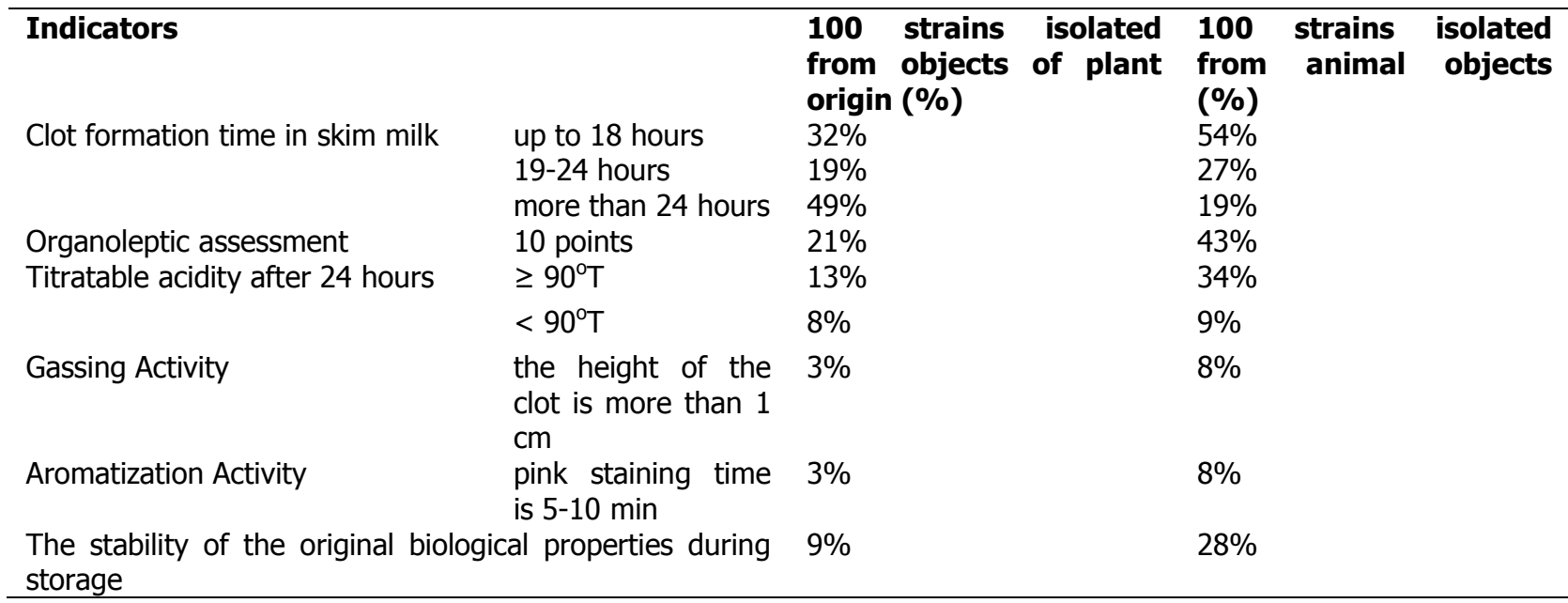

The first step in the selection of isolated strains of Lactococci was the ability of pure cultures to form in a test tube with $10 \mathrm{~cm}^{3}$ of skim milk an even, dense clot without gusts for no more than 24 hours (inoculum size is one bacteriological loop). 
Among the strains isolated from objects of plant origin, the majority (49\%) were low acid-forming agents that form a clot in more than 24 hours. The number of strong acid-forming agents that form a clot in 18 or less hours was $32 \%$. The remaining $19 \%$ of the cultures formed a clot within 19-24 hours.

The $54 \%$ of the strains, isolated from objects of animal origin, formed a clot in no more than 18 hours, $27 \%$ within $19-24$ hours. The proportion of strains with low acid formation activity (more than 24 hours) was $19 \%$.

According to the results of the first stage, $51 \%$ of strains were rejected from strains of plant origin, and $19 \%$ of strains from objects of animal origin.

The remaining strains were tested for organoleptic characteristics. Only those strains that for no more than 8 hours (inoculum size was $5 \%$ ) formed a dense, even clot on whole milk and had a pure sour-milk taste and aroma, without any extraneous smacks, were of value to us. The maximum overall score for all indicators was 10 points. According to the tasting results, $58.8 \%$ of the strains of plant origin were rejected, and $46.9 \%$ of strains of animal origin.

Lactococcal strains that received the highest score in the tasting assessment were tested for titratable acidity after 24 hours. $61.9 \%$ of strains of plant origin and $79.1 \%$ of animal lactobacilli had titratable acidity of $90^{\circ} \mathrm{T}$ or higher.

Isolated Lactococci that passed the previous stages of testing were additionally tested for activity of gas and aroma formation. The $25 \%$ of the strains of plant and animal origin turned out to be hetero enzymatic: they formed carbon dioxide and diacetyl.

For the possibility of using pure cultures of lactic acid bacteria in bacterial sourdough compositions, it is important that the strains do not lose their original biological and technologically valuable properties during storage. Therefore, strains of mesophilic lactococci, which were selected during testing for basic biological and technologically valuable indicators, were tested for the same properties at certain intervals: after 1 month, after 3 months, after 6 months. The 4 strains of the 13 strains of plant origin and 6 cultures of 34 strains of animal origin, lost their original properties and were rejected.

Thus, only 9 cultures of 100 strains of mesophilic Lactococci isolated from plant objects can be attributed to promising strains, which may be used in the preparation of bacterial starter compositions in the future. Among lactobacilli of animal origin, the proportion of strains with industrially valuable properties was $28 \%$, which is $19 \%$ higher compared to strains of plant origin (Figure 2). Promising strains of mesophilic Lactococci were included in the "Siberian collection of microorganisms" (SCM) FSBSI FASCA.
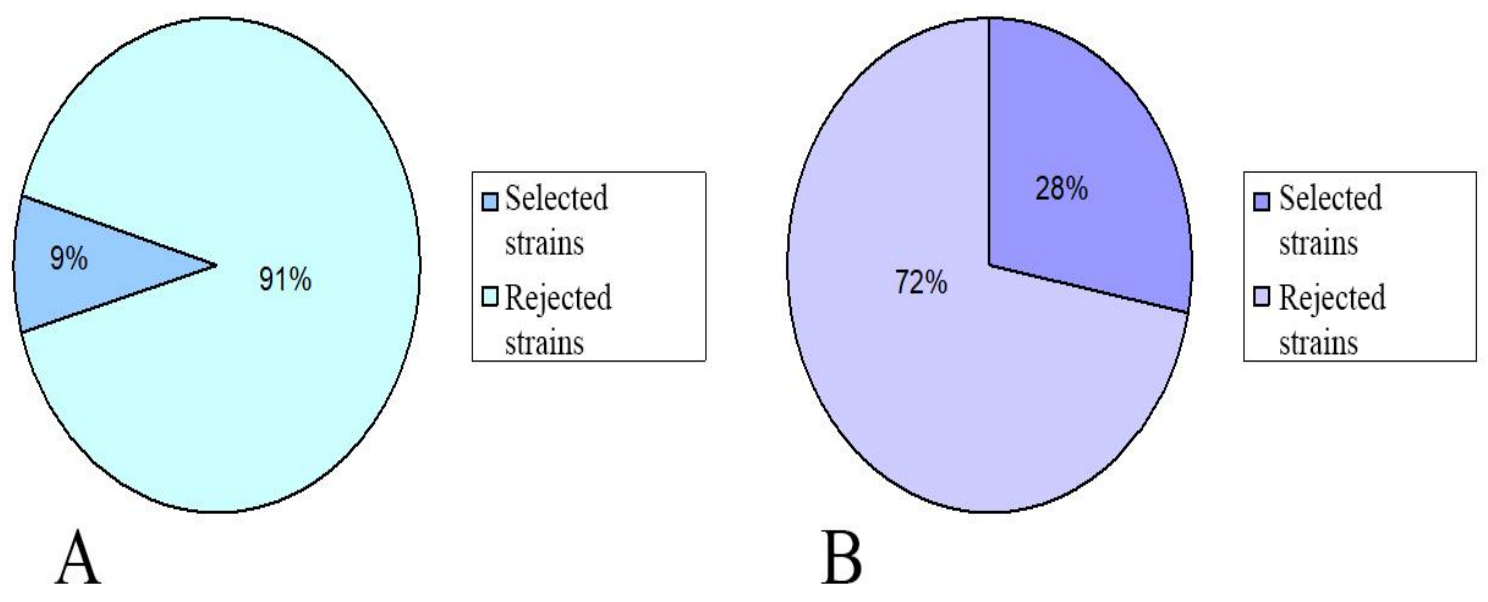

Figure 2. The results of the selection of promising strains of mesophilic Lactococci isolated from objects of natural origin. A. From objects of plant origin. B. From objects of animal origin

\section{Discussion}

Natural objects are valuable sources for the isolation of lactic acid bacteria. The newly isolated pure cultures of lactic acid bacteria with technologically valuable properties are introduced into industry collections of useful microorganisms for inclusion in microbial consortia in the preparation of bacterial starter compositions.

Lactobacilli isolated from various ecological niches can significantly differ in physiological, biochemical and technologically valuable properties, since the primary habitat of microorganisms largely determines their biological characteristics.

The main product of the metabolism of lactic acid bacteria is lactic acid. The activity of acid formation of lactobacilli is due to by their species and strain specificity, determining both biological (nonspecific antagonism by reducing the active acidity (pH) of the medium, creating unfavorable conditions for the development of opportunistic and pathogenic microflora), and technologically valuable (time of formation and quality of the clot, taste and aroma of the product) properties of lactobacilli. A comparative analysis of the strains of mesophilic Lactococci revealed that among the cultures of lactobacilli isolated from objects of animal origin (raw milk), a large proportion of active acid-forming agents with titratable acidity of $90^{\circ} \mathrm{T}$ or higher. The number of strains of animal origin, which had a maximum score when assessing organoleptic indicators, prevailed in comparison with strains of plant origin. We have not noticed differences in the ratio of homo-and hetero enzyme microorganisms between strains of plant and animal origin.

Microorganisms are characterized by significant variability and lability of their biological properties. It should be noted that often collection strains of lactobacilli lose their original technologically valuable properties, which determines the duration of their exploitation by humans. The results obtained by checking the selected cultures for the stability of their initial physiological, biochemical and technologically valuable properties showed that strains of plant origin are more labile compared to strains isolated from objects of animal origin.

The predominance of the share of mesophilic Lactococci strains of animal origin that are promising for inclusion in the industry collection of useful microorganisms, compared with microorganisms of plant origin, can be explained by the fact that raw milk - the primary habitat of selected cultures, is a more favorable environment for the life of lactic acid bacteria. In addition, strains of 
Lactococci isolated from objects of animal origin are more adapted to the environment for their cultivation and storage (skim and whole milk).

Thus, objects of animal origin are the most appropriate source of isolation of strains of mesophilic lactococci, promising for use in the dairy industry. However, objects of plant origin can also serve as sources for obtaining strains with valuable biological properties.

According to our goal, the comprehensive research of the influence of Iron(IV) clathrochelate complexes at the doses $1 / 10 \mathrm{DL}_{50}$ (76.43 $\mathrm{mg} / \mathrm{kg}$ body weight) and $1 / 5 \mathrm{DL}_{50}(152.86 \mathrm{mg} / \mathrm{kg}$ body weight) during prolonged application to the body of quails was performed for the first time. This made it possible to establish the basic patterns of metabolic disorders and physiological functions under the action of the test substance.

Daily drinking of the solution of Iron(IV) clathrochelate complexes caused the decrease of body weight of the quails in experimental groups by 3 and $5 \%$ respectively (on the 30 th day).

The tendency to increase of relative mass of kidney by $9 \%(\mathrm{P}<0.05)$ (II experimental group) and by $12 \%$ (III experimental group) and to marked decrease of relative mass of liver by 2.8 times $(P<0.001)$ (II experimental group) and 3.2 times ( $P<0.001)$ (III experimental group) compared with the control group on the 30th day shows the excessive load on the internal organs of quails under the influence of Iron(IV) clathrochelate complexes. The relative ratios of the weight of heart and spleen were lower by 14 and $50 \%$ respectively in the quails of the third experimental group (at a dose of $152.86 \mathrm{mg} / \mathrm{kg}$ body weight) compared with those in the control poultry.

The content of hemoglobin in the blood of the quails of the experimental groups was less than the control indicator by 2-34\% $(P<0.05)$. Due to the influence of the solution of Iron(IV) clathrochelate complexes the hematocrit in the blood of poultry II and III of the experimental groups during the whole experimental period was significantly lower on the 30 th day by $4(P<0.05)$ and $6 \%$ $(P<0.01)$ respectively. The number of erythrocytes in the quails of the control and experimental groups within 30 days was within the physiological values. On 30th day the number of platelets in the blood of the quails of the second experimental group were $84 \%$ $(P<0.001)$, in the blood of the quails of the third experimental group $-77 \%(p<0.001)$ from the indicator in the control group bird. The results of biochemical examination of the serum of the blood demonstrate the development of hypoproteinemia and hypoalbuminemia, the decrease of the level of glucose in the serum of the blood of quails in II and III experimental groups for only 20 days; on the 30th day his indicator did not differ from the control. Among the enzymes, only activity of alkaline phosphatase was significantly altered: in the serum of the blood of the quails in the experimental groups it was significantly higher than in the control during the whole experimental period and on the 30th day it was higher by 1.5 times $(P<0.001)$ than the indicator of the poultry in the control group. The drinking a solution of Iron(IV) clathrochelate complexes in appropriate doses led to a significant increase the levels of creatinine (hypercreatinemia) and uric acid (hyperuricemia) in serum of the blood of quails in experimental groups that it is indicating a decrease in the filtration capacity of the glomeruli of kidney. We also observed an increase in the content of Total Calcium and Inorganic Phosphorus.

\section{Conclusion}

The proportion of strains with high physiological and biochemical activity was higher among cultures isolated from objects of animal origin: according to the activity of acid formation - by $30 \%$, according to organoleptic assessment - by $22 \%$, by titratable acidity by $17 \%$, by the stability of the initial biological properties - by $13 \%$. Based on the set of biological properties, SCM was selected $9 \%$ of plant strains and $28 \%$ of animal strains from isolated mesophilic Lactococci for inclusion in the industry collection of microorganisms.

\section{References}

Ali, A.A. (2010). Beneficial Role of Lactic Acid Bacteria in Food Preservation and Human Health. Researchh Journal of Microbiology, 5(12), 1213-1221. doi.org/10.3923/jm.2010.1213.1221

Babich, O.O., Dyshlyuk, L.S., Prosekov, A.Y., Shishin, M.V. (2015). The study of antibiotic resistance and antioxidant properties of microorganisms of the gastrointestinal tract. Actual problems of science, 20-24.

Bannikova, L.A. (1975). Breeding of lactic acid bacteria and their use in the dairy industry. Moscow: Food industry, 1975.

Bannikova, L.A., Koroleva, N.S., Semenikhina, V.F. (1987). Microbiological basis of dairy production. Moscow: Agropromizdat.

Dworkin, M., Balows, A., Trüper, H.G., Harder, W., Schleifer, K.H. (2006). The Procariotes: A handbook on the biologi of bacteria, Vol. 4. USA: Springer.

Ganina, V.I., Filchakova, S.A. (2018). Ferment production in Russia. Milk processing, 3, 38-41.

Ganina, V.I., Grinevich, A.I., Loyko, N.G., Guchok, J.P. (2015). Microbiological safety of dairy raw materials. Dairy industry, $11,22-23$.

Khazagaeva. S.N., Khamagaeva. I.S., Zamblova. N.A. (2011). Tiansong San Qualitative characteristic of a multi-strain probiotic sourdough. Bulletin of VSSTU, 2(33), 16-19.

Kvasnikov, E.I., Nesterenko, O.A. (1975). Lactic acid bacteria and ways of their use. Moscow: Nauka, 60-61.

Leroy, F. (2004). Lactic acid bacteria as functional starter cultures for the food fermentation industry. Trends in Food Science and Technology, 12(2), 67-78. doi.org/10.4236/fns.2014.54051

Liu, S.N., Han, I., Xhou, Z.-J. (2011). Lactic acid Bacteria in Traditional Fermented Chinese Foods. Food research International, 44(3), 643651. doi.org/10.1016/j.foodres.2010.12.034

Mathur, S., Singh, R. (2005). Antibiotic resistance in food lactic acid bacteria - a review. International Journal of Food Microbiology, 105, 281-295.

Mayra-Macinen, A., Bigret, M. (2004). Industrial Use and Production of Lactic Acid Bacteria. In: Salminen A. (Ed.). Lactic Acid Bacteria Microbiological and Functional Aspects. New York: Marsel Deccer, Inc., 175-198.

MR 2.3.2.2327-08 (2008). Guidelines for the organization of industrial microbiological control at dairy enterprises (with an atlas of significant microorganisms). Uglich: GNU VNIIMS.

Novokshanova, A.L., Ababkova, A.A., Abramov, D.V. (2016). Search results for the optimal consortium of microorganisms in the production of specialized protein fermented milk. Bulletin of the International Academy of Refrigeration, 4, 23-29.

Orlova, T.N., Irkitova, A.N. (2015). Isolation of lactic acid bacteria from objects of natural origin and selection among them of the strains most promising for creating bacterial starter cultures and concentrates. Sat. Art. conf.: "Biotechnology and society in the XXI century, 232235.

Panesar, P.S. (2011). Fermented Dairy Products: Starter cultures and Potential Nutritional Benefits. Food and Nutrition Sciences, 2(1), 4751. doi.org/10.4236/fns.2011.21006 
Rozhkova, T.V. (2006). The Russian market of starter cultures. Dairy industry, 3, 23-24

Shan, N.P. (2007). Functional cultures and Health Benefits. Internationaj Dairy Journal, 17(11), 1262-1277. doi.org/10.1016/j.idairyj.2007.01.014

Sharma, R., Sanodiya, B.S., Bagrodia, D., Pandey, M., Sharma, A., Bisen, P.S. (2012). Effecacy and Potential of Lactic Acid Bacteria Modulating Human Health. Internaytional Journal of Pharma and Bio Sciences, 3(4), 935-948.

Solovyova, I.V., Tochilina, A.G., Novikova, N.A. (2010). Study of the biological properties of new strains of the genus Lactobacillus. General biology. Bulletin of the Nizhny Novgorod University. N.I. Lobachevsky, 2(2), 462-468.

Steele, J., Broadbent, J., Kok, J. (2013). Perspective on the Contribution of Lactic Acid Bacteria to Cheese Flavor Drvelopment. Current Opinion in Biotechology, 24(2), 135-141. doi.org/10.1016/jcopbio.2012.001

Tsugkiev, B.G., Kabisov, R.G., Petrukovich, A.G., Ramonova, E.V. (2015). Characterization of lactic acid bacteria isolated in North OssetiaAlania and their use. Collection of articles of the conference "Biotechnology and Society in the XXI Century", 282-288.

Vos, P., Garrity, G., Jones, D., Krieg, N.R., Ludwig, W., Rainey, F.A., Schleifer, K.-H. \& Whitman, W.B. (2009). Bergey's Manual of Systematic Bacteriology, 2nd ed., Vol. 3. New York: Springer-Verlag, USA.

\section{Citation:}

T.N. Orlova, R.V. Dorofeev, A.N. Irkitova, I.A. Funk, A.V. Grebenshchikova (2019). Biological feature of lactic acid bacteria in distinct ecological niches. Ukrainian Journal of Ecology, 9(3), 384-388.

(cc) $\mathrm{EY}$ This work is licensed under a Creative Commons Attribution 4.0. License 